\title{
Fulgores vinculares por una historiografía situada Echando luz a las formas obscuras del arte latinoamericano
}

\author{
Bond Glares for a Situated Historiography \\ Shedding Light upon the Dark Forms of Latin American Art
}

\author{
Valentina Valli \\ valenvalli@hotmail.com \\ Instituto de Investigación en \\ Producción y Enseñanza del Arte \\ Argentino y Latinoamericano. \\ Facultad de Bellas Artes. Universidad \\ Nacional de La Plata. Argentina \\ Recibido: $14 / 11 / 2018$ \\ Aceptado: 23/2/2019
}

\begin{abstract}
Resumen
En el presente artículo nos proponemos reflexionar y abordar los vínculos posibles entre los teóricos latinoamericanos Rodolfo Kusch (Argentina) y Ticio Escobar (Paraguay). Estableciendo relaciones entre algunos conceptos en sus escritos (como la representación o el debate forma-contenido), intentaremos ahondar en los puntos en común entre las concepciones estéticas de ambos autores de nuestra Patria Grande. De este modo, se pretenderá divisar nociones acerca de los contenidos propios de lo artístico creacional, que no son sometidos a las nociones (extranjeras y fundamentalmente europeas) preestablecidas, sino que las reutilizan y reformulan y echan luz a aquellas potencialidades resguardadas, que desde estas otras ópticas permanecen sombrías y hasta intimidantes.
\end{abstract}

\section{Palabras clave}

Kusch; Escobar; representación; forma; contenido

\section{Keywords}

Kusch; Escobar; Representation; Form; Content

\begin{abstract}
In this article, we propose to reflect and address the possible links between Latin American theorists Rodolfo Kusch (Argentina) and Ticio Escobar (Paraguay). Establishing relationships between some concepts in his writings (such as representation and the form-content debate), we will try to delve into the points in common between the aesthetic conceptions of both authors of our Great Homeland. Thus, we will try to discover notions about the contents of the artistic creational, which are not subject to pre-established notions (foreign and fundamentally European), but re-use and re-formulate them, throwing light on those potentialities sheltered that from these other optics remain somber and even intimidating.
\end{abstract}


1 Hacemos uso del concepto de Patria Grande en alusión a América Latina, pero intentando reforzar el sentido vincular entre estos países latinoamericanos, apelando a su unidad y pertenencia común. Si bien esta noción se remonta a las Guerras Independentistas Hispanoamericanas, es actualmente recobrada y coopera a las teorías de Escobar y de Kusch, quienes abogan por un pensamiento propio, local y situado que nos emancipe intelectualmente.
Muchas veces, al ahondar en teorías fundadas en nuestra propia Patria Grande, ${ }^{1}$ es posible vislumbrar ciertos nexos que se entretejen y nos permiten divisar puntos de conexión que enriquecen y profundizan nuestros análisis. Siendo ésta una de las vías propias de la labor historiográfica, en este artículo nos proponemos atender las posibles relaciones existentes entre los conceptos utilizados por dos teóricos latinoamericanos: Rodolfo Kusch (19221979), de la Argentina y Ticio Escobar (1947), de Paraguay.

Además de haber sido contemporáneos entre sí por algunos años (pese a que los escritos de Escobar sean más actuales y aún continúe generando producción teórica), podríamos decir que sus lineamientos teóricos abogaron por redignificar el arte americano (e indígena). De esta manera, contribuyeron a formular teorías situadas que, si bien se nutrieron de pensadores internacionales, fueron adaptadas crítica y reflexivamente a la realidad de América Latina, entendiendo sus problemáticas políticas, sociales, económicas y, fundamentalmente, culturales.

Sin ánimos de abarcar extensiones perpetuas, pretendemos trazar posibles vínculos enriquecedores para el campo del arte entre ambos autores. Ticio Escobar plantea que la representación surge como síntesis de la forma y el contenido, pero ante el triunfo del mercado en nuestra era capitalista, esta forma ya no es patrimonio de lo artístico como en otras épocas. Lo único que sigue perteneciendo al terreno de lo netamente artístico es, entonces, su contenido sígnico, el cual debe vagar oscilante para encontrar formas precarias y transitorias que le den asilo y, así, permitir su enunciación artística. Debido a esto, el arte actual se ha visto en la necesidad de peregrinar por los senderos de nuevas e impensadas formas, que desafían nuestros parámetros de belleza y hacen visible aquello del orden de lo amorfo o, por qué no, lo tenebroso.

En este sentido, creemos que la estética de lo tenebroso planteada por Kusch nos otorga posibles vías de acceso para lograr mayor profundización en lo que plantea Escobar. Para el filósofo argentino, «una estética de lo americano no puede reducirse a un análisis de las formas y de lo dado porque nada de esto tiene real consistencia entre nosotros» (Kusch, 1955, s. p.); por lo tanto, lo realmente vital en las producciones latinoamericanas podría ser equiparado a ese contenido errante que plantea Escobar. El verdadero arte, o al menos el que vale la pena desde estas ópticas, «surge así de un miedo original que cuestiona a lo amorfo su falta de forma" (Kusch, 1955, s. p.) y contradice los cánones occidentales, europeos y cristianos heredados, e inaugura formas alternativas de entender la potencialidad artística de las diversas producciones latinoamericanas, ya no devotas ni sumisas. 
Es así que intentaremos indagar sobre esta red relacional que se formula entre estas concepciones estéticas de ambos autores de nuestra Patria Grande al divisar sus concepciones acerca de este contenido propio de lo artístico creacional, y que no se somete a las nociones (extranjeras y fundamentalmente europeas) preestablecidas, sino que las reutiliza y las reformula echando luz a aquellas potencialidades resguardadas, que desde estas otras ópticas permanecen sombrías y hasta intimidantes.

\section{Debajo de la forma}

La representación, según Escobar (2015), surge como resultado o síntesis de dos movimientos: el del signo (concepto) y el de la forma (imagen). Sin embargo, en ella perdura infinitamente una distancia entre el objeto en sí y su representación, ya que esta última jamás podrá ser ese objeto plenamente simbolizado. En un acto de Belleza, la representación nos revela una Verdad, parte de su esencia, que no es más que el secreto que encierra esa distancia y que acecha insidiosa y palpitante en la obra, y que nos atrae y seduce hacia ella.

Esta idea ha ido mutando a lo largo de los años, siendo así que las representaciones clásicas, por medio de la mímesis, han ido intentando corregir esa ausencia, esas sombras generadas por el hecho de ser y no-ser a la vez, para darles prevalencia a las bellas formas y disimular su realidad sombría. No obstante, el panorama del arte contemporáneo, donde prima el concepto y la narratividad por sobre los recursos formales, acepta estas sombras, este carácter negativo, que termina por conformar la autonomía más propia y genuina del ámbito artístico.

Esta crisis antiformalista también da cuenta de una reacción ante el esteticismo generalizado, producto de la nueva era de la reproductibilidad técnica. La utopía emancipatoria que se lograría a través del arte (o política) según el Iluminismo, acabó siendo cooptada por el mercado, el cual convirtió este sueño de liberación en rentabilidad funcional al sistema capitalista. El mercado termina por quitarle al Arte su patrimonio sobre la Belleza y lo estético, ahora invadido por el diseño, la publicidad y los medios, $y$, de esta forma, se le obliga a refundar un lugar propio.

Para Kusch (1955), lo propiamente artístico queda truncado si se parte de vivencias elaboradas, para arribar a formas rigurosamente preestablecidas, que podrían ser relacionadas a la intromisión del mercado en la producción de objetos artísticos que plantea Escobar. Es así que para Kusch la vida (incluyendo en ella lo político, lo social, lo económico, lo cultural) queda escindida de la producción artística que, partiendo únicamente del plano 
formal, se olvida de que si fuera real no habría forma que cuaje para ella. Sin acto estético, la utopía que plantea lo artístico pierde la fuente donde se halla su más verdadera vitalidad.

En simples palabras, el Arte ha perdido su territorio autónomo y deja de ser considerado y valorado por cumplir con ciertos requisitos estéticos. Por lo tanto, si lo expresamente estético ya no es de su patrimonio se ve forzado a desviar su mirada a contenidos extraartísticos, por fuera de sí, para mantener su función: el mundo de afuera, la historia que pasa, la cultura; en fin, la confusa realidad. Es así que el Arte deja de buscar la conciliación con el todo a través de la belleza formal y se vuelca a su contenido simbólico considerando sus condiciones de enunciación, sus alcances pragmáticos, su impacto social, su inscripción histórica, su densidad narrativa o sus dimensiones éticas. Esta metástasis de su forma no es más que su intento de subsistencia ante el problema de la indiferenciación provocada por un esteticismo masivo. El arte se termina por conformar como crítica del esteticismo globalizado.

Con lo que hasta aquí ha sido expuesto, es posible comprender que lo realmente artístico, aquello potencialmente transformador del arte o sus enunciaciones más reveladoras yacen, para Escobar, en aquello que es de naturaleza irrepresentable. De manera un tanto análoga, podría ser expuesta la postura que plantea Kusch (1955): «El arte surge así de un miedo original que cuestiona a lo amorfo su falta de forma» (s. p.). En contraposición a esta cualidad latinoamericana, que irrita y atemoriza a los cánones occidentales y europeos, resulta imprescindible acentuar lo visible y formal en el arte reprimiendo aquello que se escapa a los parámetros de la estética tradicional. Esta misma, más que el proceso creacional de la obra, su génesis, valoriza el producto y deja prácticamente afuera al artista y se centra en una concepción que prioriza lo objetual y lo formal del arte.

No obstante, para Ticio Escobar (2015), la representación no puede perder su forma, ya que su relación primigenia con ella es indisoluble y necesita claramente de su función mediadora. En tal sentido, resulta preciso modificarla, reformarla, dado que la forma basada en la sensibilidad, el gusto y la belleza ya no es útil. Esos nuevos contenidos de los que se hará cargo el arte conllevan el peso de la indiferenciación que son equivalentes a la transformación de la forma artística, como dice Escobar (2015), «tanto el exceso como la falta dejan sin lugar al arte» (p. 29).

En palabras del filósofo argentino Rodolfo Kusch, tenemos que reflexionar sobre nuestro propio problema $y$, de modo hermenéutico, comprenderlo en la medida que encontramos sentido a aquello que interpretamos. De esta forma, se intenta proponer una interpretación de los procesos artísticos como parte de los 
mapas políticos, sociales y culturales locales, prefiriendo así decir que los artistas, más que describir contextos, producen desde los contextos. Como el propio autor explica «una estética de lo americano no puede fincar en una estética del arte sino del acto artístico, precisamente porque este incluye lo tenebroso cuando contempla ese proceso brumoso que va de la simple vivencia del artista a la obra como cosas» (Kusch, 1955, s. p.). Esto implica entender el traspaso de aquello puramente vital, dinámico, hacia otro que no lo es:

\footnotetext{
[...] el arte se vuelca con violencia, como venciendo una resistencia, ya que expresa contenido que adopta una forma. [...] Hay un proceso del arte como acto, la superación de una falla esencial en lo humano, por la que el arte es una solución para un aspecto fallido de la existencia, precisamente aquél por el cual la vida y la inteligencia se oponen [...]. Es una oposición por contradicción, ya que el segundo elemento encierra la negación del primero [...]. El arte entra así en un proceso general de lo humano porque subsume el mundo vital al mundo intelectual para fijar y contener (Kusch, 1955, s. p.).
}

Quizás en este sentido, el arte para Escobar, por más que oscila sin una expresión física que le sea claramente propia, es consciente de que arrastra una pretensión metafísica nacida de sus orígenes y que es la que le otorga aún vigencia y una potencia negativa. Su convocatoria de lo real está destinada al fracaso, pero es su insistencia en ello lo que define realmente su trabajo. Por lo tanto, el arte debe hacerse cargo de esta falla negativa, para revertirla y hacerla su potencia, su fuerza, consiguiendo así descubrir de su opacidad el aval de la palabra.

Es allí donde reside lo tenebroso del arte, bajo el signo, la obra resguarda una vitalidad postergada frente a lo social, al cual le cuestiona su sobrevivencia. Lo más auténtico del gran arte estriba en que es una respuesta plástica a esa pregunta primordial que el grupo social (por intermedio del artista) se ha hecho sobre sí mismo (Kusch, 1955). Así, la obra propicia un canal entre lo tenebroso y su transición hacia la luz, y descubre o reconoce en ello un aspecto de lo vital que nos resulta obscuro.

Más allá de la persistente falta de definición de lo expresamente artístico, no podemos afirmar, como había anunciado Georg Wilhelm Friedrich Hegel (1989), que el arte ha muerto. La mutación constante de su forma y contenido muchas veces concluye por determinar su condición artística en la búsqueda de nuevos entes legitimadores. El contexto, la posición, el espacio o la condición de enunciación cobrarán una nueva importancia y se harán responsables de este tipo de labor. Por lo tanto, la imagen se transforma en la mediadora entre esa forma y contenido, y hace posible traer 
al campo artístico cosas no pensadas para ese circuito, pero que dentro del ambiente adquieren contundencia formal y se transforman en obra: «El objeto deviene en artístico al ser ubicado en cierto contexto: no solo en cuanto se muestra allí sino en cuanto hace saber que allí está ubicado» (Escobar, 2015, p. 34).

Para agregar aún mayor complejidad al asunto, al arte aún le queda optar de qué forma se relacionará con este nuevo contexto donde ha triunfado el mercado y su estetización masiva: ¿debe el arte convertirse en parte de esta nueva dinámica, sucumbir al papel de mercancía, o debe resistirse a esta banalización propuesta por el mercado?

Ante tal dilema, Escobar rescata el pensamiento benjaminiano, fundamental para el análisis de este período. La búsqueda de un acercamiento y accesibilidad del arte a las masas hará a Walter Benjamin proponer la renuncia al aura (halo de originalidad, la irradiación del deseo que produce la distancia). Esto supone dos cuestiones, por un lado, cancelar el aura desmonta la autonomía formal del arte y le permite abrirse a terrenos por fuera de la bella forma. Por otro, anula la distancia de la representación y la experiencia intensa de la recepción, lo que mantiene viva la disyunción de la problemática artística. A su vez, sin la distancia que imponen sus formas, el arte perdería su signo exclusivista que ha marcado históricamente su lugar de estatus dentro de las clases altas.

En este sentido, Benjamin postula como meta la liberadora politización del arte en respuesta a la estetización política fascista, siendo aún viable una apuesta a las características transformadoras del aura. Sin embargo, actualmente sabemos que tal utopía ha fracasado, siendo el mercado el que se hace cargo de la reproductibilidad, mediante industrias culturales y medios masivos de comunicación. No obstante, lo que a Escobar le interesa es que ese mercado no anula del todo el aura, ya que rescatar reminiscencias de la misma le sirve para fabricar mercancías que seducen mediante un doble juego: la masificación del producto, un acercamiento cuasi violento; el armado fetiche del mismo, que encubre su origen industrial y subraya su valor exhibitivo, es decir, el objeto de consumo es re-auratizado por un cierto alejamiento que le da espacio a la mirada $y$, por ende, al deseo. En su momento, Benjamin pensó que si el arte se convertía en mercancía se llegaba a un tope en el cual era posible visibilizar las secretas vulnerabilidades capitalistas, y era justamente allí el lugar o el momento donde hallar su germen emancipador. De esta forma, no quedaría perdido del todo el potencial de lo artístico, subsumido ante al mercado. Esto es lo que le da pie a Ticio Escobar para sustentar sus teorías y revalorizar la función liberadora de los contenidos del arte. 


\section{Reencuentro con la potencia}

Luego de lo expuesto, volver a la representación nos permite rescatar la disputa que encierra esta idea entre ser y aparecer. Lo esencial se muestra en una presentación única. Pero, por más próxima que pueda estar esta representación, existe una distancia insoldable debido a que nunca termina de presentarse, sigue siendo apariencia de algo. Por lo que la imagen siempre está marcada por esta dinámica de presencia-ausencia del ser, donde lo real irrepresentable queda palpitando como una oscura promesa de sentido.

La mirada juega un papel fundamental en esto, ya que cuando la obra es expuesta ante la mirada del espectador, el objeto se divide entre su identidad y su apariencia (su imagen). En otras palabras, quedaría escindido entre una presencia y ausencia de sí, y su imagen sostenida en una pérdida: «Ver (algo) es perder (algo)» (Escobar, 2015, p. 42). A la vez, el objeto auratizado tiene el poder de devolver la mirada a su espectador, quien también quedará dividido entre su ser y su imagen y lo inviste con el poder del deseo. Como dice Escobar (2015) retomando a Jacques Lacan:

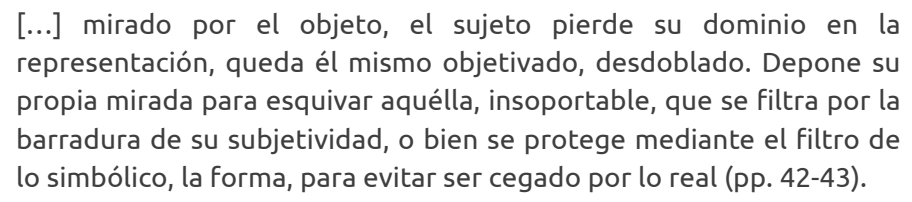

De esta manera, se anula la posibilidad de una mirada objetiva del objeto, el aura produce una refracción de la mirada que nos obliga a darnos cuenta del peso necesariamente subjetivo que allí reside.

En este sentido, volver a estas reflexiones latinoamericanas nos permite avizorar esta potencia que, a modo de reserva poética, nos interpela en el arte. La vuelta a lo propio de lo humano, a aquello que no pudo ser apropiado por el mercado, implica que seamos responsables y adoptemos actitudes originales para reencontrarnos en ese irrepresentable que tanto dice de nuestra sociedad.

No perder esta red de vínculos conceptuales que generan diversos intelectuales locales nos abre a proseguir en esta tarea historiográfica incansable de generar teorías del arte situadas. Solo mediante esta labor es posible acercarnos a la comprensión de nuestra propia producción artística y cultural, echando luz a lo obscuro y encontrando allí posibles respuestas de lo que nos es propio. 


\section{Referencias}

Escobar, T. (2015). Imagen e intemperie. Las tribulaciones del arte en los tiempos del mercado total. Buenos Aires, Argentina: Capital Intelectual.

Hegel, W. G. F. (1989). Lecciones de estética (Trad. A. Brotóns). Madrid, España: Akal.

Kusch, R. (1955). Anotaciones para una estética de lo americano. Comentario, (9). Recuperado de http://latitudeslatinas.com/download/artigos/ Rodolfo-Kusch-Anotaciones-para-una-estetica-de-lo-americano.pdf 